\title{
EXPERIMENTAL WEAR STUDY BETWEEN PISTON RING AND CYLINDER LINER PAIR USING JATROPHA OIL AS LUBRICATING OIL
}

\author{
R. R. NEELA RAJAN ${ }^{1} \&$ R. RAJESH ${ }^{2}$ \\ ${ }^{1}$ Department of Aeronautical Engineering, Noorul Islam University, Kumaracoil, Tamil Nadu, India \\ ${ }^{2}$ Department of Mechanical Engineering, Noorul Islam University, Kumaracoil, Tamil Nadu, India
}

This paper reports the experimental study of wear behaviour for the pair of cylinder liner and piston ring. Reciprocating wear process parameters were optimized for minimum weight loss of piston rings, based on the response surface methodology with three process parameters such as load, sliding velocity and quantity of oil. The tests were conducted under two different types of oil such as Jatropha oil and SAE15W40 oil. It is perceived that sliding velocity is the most important factor for influencing weight loss of piston ring under both the oils. The tests under Jatropha oil gives less weight loss of piston rings, when compared with that of under SAE15W40 oil. The experimental results are in exact consonance with the values obtained from the theoretical model.
\end{abstract}

KEYWORDS: Wear Behaviour, Jatropha Oil, SAE15W40 Oil, RSM \& Process Parameters

Received: May 02, 2017; Accepted: May 30, 2017; Published: Jun 12, 2017; Paper Id.: IJMPERDJUN201730

\section{INTRODUCTION}

The motor car is one of the most important machines that used in day to day life. The motor car itself consists of many tribological components such as a reciprocating internal combustion engine, transmission systems, braking systems, lubricating system and cooling systems [1]. Among tribological components, the reciprocating internal combustion engine is a major propulsion device for the motor car. The purpose of the internal combustion engine is to develop mechanical power as the reciprocating motion of the piston inside the engine cylinder by releasing chemical energy from the oxidation of the fuel. The popularity of the reciprocating internal combustion engine is proved by its ability to relied on its operation, performance and capable of turning to its tasks. However the thermal efficiency is relatively low, due to energy of the fuel is spent up wastefully as heat loss and friction. The engine also creates pollution in the atmosphere resulted from hydrocarbon, smoke intensity, and NOx (nitrogen oxides) emissions and carbon dioxide (CO2) emissions. The current trend is to develop reciprocating internal combustion engines with higher engine performance and reduced emissions [2]. The engine performances are directly depends upon the life of its components like piston with piston rings, cylinder with cylinder liner, cylinder head, crankshaft, cam shaft, connecting rod etc and its lubricating oil to lubricate these components [3].

Among these components of reciprocating internal combustion engines, the piston is a vital component which acts a main part of the reciprocating internal combustion engine, slides in the cylinder liner. Piston is commonly made of aluminium or cast iron alloys and which transforms the energy of the expanding gasses into mechanical energy. In operation, the piston translates in the transverse direction and revolves around the wrist pin axis and it is also driven axially to and fro within the cylinder liner [4]. There are several piston rings around the 
piston to prevent the combustion gasses from bypassing the piston and to keep friction to a minimum. There are three functions of piston rings. They serve as a seal for the combustion chamber so that there is no transfer of gases from the combustion chamber to the crankcase. They are also regulating a film of lubricant to the walls of the cylinder. The rings also are important to transfer the heat of the piston to the cylinder walls. These piston rings must fulfil these three roles with a minimum of friction and wear, in order to improve the component life. So, the piston rings are important element in the internal combustion engine.

In operation, mechanical wear causing frictional losses which takes place in contact surface between the piston ring and cylinder liner of internal combustion engines, which plays a vital role for reducing the mechanical efficiency [5]. But, the piston ring is one of the most important sources of friction in the reciprocating internal combustion engine when compared with that of the cylinder liner under normal range of engine speeds and loads [6-9]. About 50\% of the frictional losses occur in the piston-cylinder assembly of internal combustion engine, out of which piston rings take a part of 70-80\% of frictional losses [10-14]. It is concluded that in internal combustion engine, the piston ring is the most complicated tribological element, because huge amount of frictional losses comes from it [15]. The effective lubrication is required for the surface of contact between piston ring and cylinder liner of piston-cylinder assembly in order to reduce friction and wear with minimum emissions expelled to the environment. This task is particularly difficult given the wide range of operating conditions of load and sliding velocity, type of lubricating oil and chemical reactivity experienced in the engine.

\section{LITERATURE SURVEY}

A lubricant is a liquid substance applied in the contact place between two moving parts for reducing friction, improving efficiency and reducing wear between them [16]. Jatropha is a non edible plant that was found recently and derived from Jatropha Curcas plant which used as feedstock for biodiesel and also bio-lubricant for reducing wear between two contact surfaces of moving parts [17]. The global consumers eager to use plant oil based lubricants because of its advantageous to the environment and the reason for that it is extracted from renewable resources. Jatropha oil is non-edible oil because it is not used with food products because of the presence of toxic esters which results that it is not demanded for the food manufacturing companies [18].

There were different studies have been conducted on the reciprocating wear tests under various lubricating oils. Murat Kapsiz et al have investigated that the tribological behaviour of cylinder liner (CL) and piston ring (PR) pair were optimized for low weight loss and friction based on the Taguchi method under various process parameters such as sliding speed, load and type of oil. It is concluded that sliding speed have the most vital parameter for weight loss as well as friction of CL/PR pair and the interaction of sliding speed and the type of oil influenced on piston ring weight loss [15]. Karamis M.B. et al have examined that the wear behaviour of the piston ring made up of gray cast iron coated with AlMo-Ni under with and without lubricated conditions at elevated temperatures. Wear tests were accomplished by using a universal wear testing machine with different load conditions, and at elevated temperatures under lubricated and dry conditions [19].

Tung SC and Gaob H have evaluated that the friction and wear performance of coated piston rings reciprocated on the cylinder liner made of cast iron in fully-formulated engine oils with the help of reciprocating wear test tribometer [20]. Ryk.G have conducted the test with the help of reciprocating test rig consisting of pair of piston rings and cylinder liner in order to evaluate the laser surface texturing (LST) effects on reduction of the friction occurs in piston rings. The performance of a partial LST cylindrical rings were optimized and compared it with conventional type non-textured barrel 
shaped rings were studied and investigated that the partial LST piston rings showed about $25 \%$ of friction reduction than that of conventional type non-textured barrel shaped rings[21]. John J. Truhan et al have conducted the reciprocating tests on the heavy-duty diesel engine to evaluate wear and behaviour of the friction for materials of the piston ring and cylinder liner. The oil conditions and its effects are considered as vital factors in the work [22].

J. Michalski and P. Wos have investigated that the crucial effect of the initial surface roughness of cylinder liners and the wear occurs between the surface of contact between the piston and cylinder pair [23]. Tushar Hire and V.N. Bertaria have evaluated that the ring friction at various engine speeds and at various crank angle position for SAE15W and SAE30W lubricating oils and also the important parameters such as ring pressure and the maximum bending stresses on the ring friction were studied [24]. Roop Lal et al have investigated that the hydrodynamic oil film at the interface between the different rings and liner while running of an internal combustion engine. Thin lubricating film reduced both engine wear and friction. The frictional force at the rings is determined by the load on the ring, the material surface properties and the lubrication conditions [25].

U.I. Sjodin and U.L.O. Olofsson have prepared the test rig in order to simulate the sliding motion of piston in a radial piston hydraulic motor and examined that the wear occurs between piston ring and piston groove on the account of mass loss and changes in form and surface roughness. The test concluded that wear occurs on the piston ring is up to ten times less than that of the piston ring groove. The most important design variable for occurring of wear was the length of the support surface and so the piston groove was not supported with any support surface based on preferred design of piston groove [26]. T. H. C. Childs and F.Sabbagh have performed the tests to study the wear mechanisms, and showed the importance of the high cycle metal fatigue on chemical reaction film wear. A grey and a carbidic iron were the two types of the piston rings used for this analysis of wear behaviour using design parameters such as specific loads and the sliding velocity. The tests were conducted by varying the specific loads from 20 to $400 \mathrm{MPa}$ with a constant sliding velocity as 0.4 $\mathrm{m} / \mathrm{s}$. The engine tests produces worn surfaces seemed as bright in an optical microscope, while patchy non-metallic films have covered pin-on-ring test surfaces, resulted that the two types of the wear mechanisms were different with one another. Moreover, the rate of wear, coefficient of friction, plastic index and percentage of metallic contact were measured using pin-on-ring tester. But the specific rates of wear were not correlated with any parameters of contact stress severity [27].

A. V. Sreenath and N. Raman have investigated that roughness of the rings and liner of an reciprocating engine depend upon particularly on the linear wear during running-in. Running-in wear studies was carried out on a compression ignition engine showed that the linear wear of the cylinder liner increased with increase in the initial surface roughness of the liner at certain dead centre locations of piston rings while the linear wear of the piston rings and cast iron liner reduced with raising the magnitude of load but the mass wear raised with raising of the load [28]. S. Mezghania et al have analysed the hydrodynamic contact region between the cylinder liner and ring by considering the real topography of the cylinder liner in order to predict the friction model. The main role of this model is to derive the solution for the average Reynolds equation and explains the influences of the irregularity of the surface on the lubricant flow under the condition of hydrodynamic lubrication [29].

Priest $\mathrm{M}$ and Taylor $\mathrm{CM}$ investigated that as the components of the piston assembly experienced large variations in load, sliding velocity, temperature and lubrication regime, they are considered as the most complicated tribological components[30]. Staffan Johansson et al studied that the wear, friction and change in surface morphology when the piston ring reciprocating on a cylinder liner at boundary and mixed lubrication regimes aims to reduce the wear and loss of 
friction [31]. Priest $\mathrm{M}$ et al reported that the new model is to be applied on the piston ring pack of a diesel engine. First, the model is applied to Caterpillar 1Y73 single-cylinder diesel engine which is used to investigate the performance of piston ring pack before and after periods of running under lubrication, at constant sliding velocity and load condition. It is established that the change in tribological behaviour with observed wear in the engine. Secondly, the model is used to predict the lubrication and wear of the top compression ring from the same engine. From this study, it is concluded that the piston ring profile evolution with time and it depends up on interactions between the lubrication and wear [32].

Bilal $\mathrm{S}$ et al have investigated that the feasibility of producing bio-lubricant by making the modification in the chemical property of the Jatropha crude oil. The modification is helpful for improving the extracting capacity of the Jatropha crude oil by its lubrication properties. The performance of the Jatropha bio-lubricant was compared with engine lubricant by their physicochemical properties [33].

John $\mathrm{J}$ et al determined that the wear and friction behaviour for piston rings and cylinder liners of heavy duty diesel engine with different methods and the tests were carried out on the typical diesel engine under various types of lubricants with the same methods, which resulted the test sensitivity for various test temperatures ranged from 25 to 100 ${ }^{\circ} \mathrm{C}$. Sensitivity of the tests under lubricant condition was evaluated under a various kinds of oils such as mineral oil, and fully formulated $15 \mathrm{~W} 40$ heavy duty oil [34].

In this study, Jatropha Curcas oil is used as lubricating oil between piston ring and cylinder liner and compared the Jatropha Curcas oil with ordinary SAE 15W40 lubricating oil. The main objective of this study is to examine the tribological characteristics of interaction between the piston rings and cylinder liner by applying different lubricating oils such as Jatropha Curcas oil and 15W40 heavy duty oil using response surface methodology under varying testing conditions.

\section{EXPERIMENTAL SETUP}

The wear behaviour between piston ring and cylinder liner for the reciprocating internal combustion engine were simulated using a reciprocating engine wear testing machine, which is shown in figure 1.

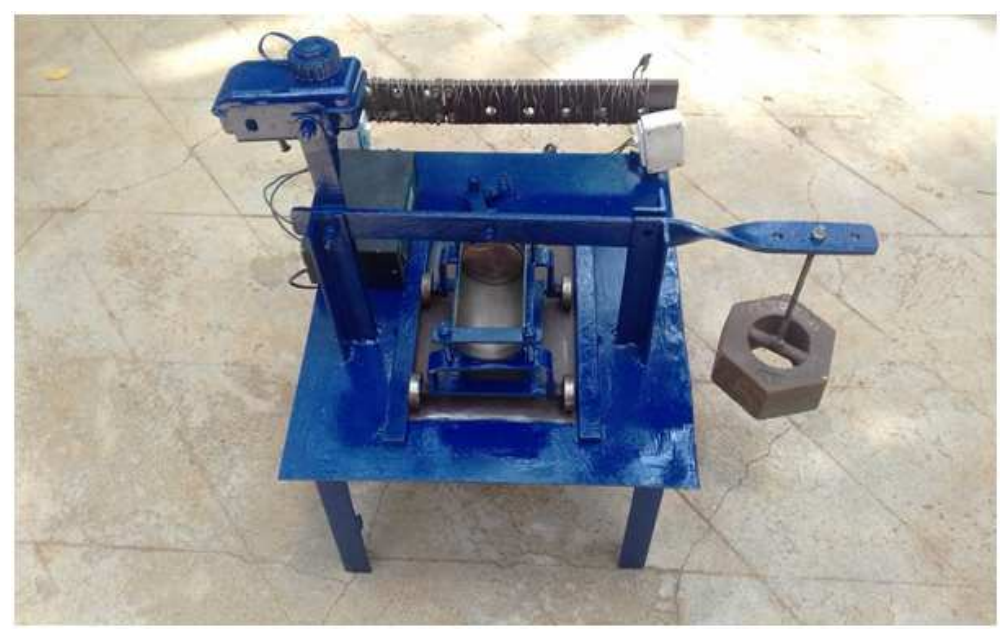

Figure 1: Photographic View of Wear Testing Machine

The wear testing machine consisting of piston ring holder, cylinder liner, rail operated by motor, speed regulator, oil tray and hanger weight. The piston ring can be attached and dismantled in a piston ring holder. The bottom of the 
machine is having the cylinder liner attached to it. Therefore, the piston ring can reciprocate on the cylinder liner at a high frequency. This process is simulating the motion of the piston ring inside the engine cylinder line at room temperature. Load on the piston ring was applied on the hanger using dead weights. The piston rings are made of cast iron with chrome coated and the cylinder liner at the bottom of the bottom of the machine is made up of cast iron. The test specifications shown in Table 1 and Piston ring and cylinder liner specifications are presented in Table 2.

Two fully formulated oils as Jatropha oil and SAE15W40 oil were applied between piston ring and cylinder liner as test lubricants and tested under the same sliding conditions. Properties of the Jatropha oil and SAE15W40 oil are shown in Table 3. Based on the above literatures, in an internal combustion piston engine, about $50 \%$ of the friction losses occur because of the piston-cylinder assembly, of which 70-80\% friction losses occurs due to piston rings. So it was important to pay more attention on wear of the piston rings in the piston-cylinder assembly. After testing, the weight loss of the all piston rings was calculated under different process parameters such as test load, sliding velocity and quantity of oil. An analytic balance is having a sensitivity of $0.1 \mathrm{mg}$ was used for weighing the piston rings.

Table 1: Test Specifications for Both Oils

\begin{tabular}{|l|c|}
\hline \multicolumn{1}{|c|}{ Test Specifications } & Values \\
\hline Load in N & $50-70$ \\
\hline Sliding Velocity in cm/min. & $1200-1800$ \\
\hline Quantity of oil in $\mathrm{ml}$ & $10-30$ \\
\hline
\end{tabular}

Table 2: Specifications of Piston Rings and Cylinder Liner

\begin{tabular}{|l|l|}
\hline \multicolumn{1}{|c|}{ Components } & \multicolumn{1}{c|}{ Specifications } \\
\hline Piston rings & Cast iron with Chromium coated \\
\hline Cylinder liner & Cast iron \\
\hline
\end{tabular}

Table 3: Properties of Oils

\begin{tabular}{|l|c|c|}
\hline \multicolumn{1}{|c|}{ Viscosity Grade } & SAE 15W40 & Jatropha Oil \\
\hline Viscosity at $30^{\circ} \mathrm{C}\left(\mathrm{mm}^{2} / \mathrm{s}\right)$ & 178.01 & 52.6 \\
\hline Viscosity Index & 140 & 220.7 \\
\hline Flash point $\left({ }^{\circ} \mathrm{C}\right)$ & 229 & 300 \\
\hline Pour point $\left({ }^{\circ} \mathrm{C}\right)$ & -27 & -7 \\
\hline Specific gravity at $15^{\circ} \mathrm{C}\left(\mathrm{kg} / \mathrm{m}^{3}\right)$ & 0.88 & 0.923 \\
\hline
\end{tabular}

\section{Design of Experiments}

A three-level-three-factor Box-Behnken was used for performing the optimization studies to reduce the wear of piston ring as to improve the performance of reciprocating internal combustion engine. The main benefit of the BoxBehnken method is that the Box-Behnken design at $95 \%$ confidence level regarding statistical predictability when compared with some extent with that of central composite design at some extreme conditions [35]. A total of 15 experiments were carried out separately, for obtaining the experimental response of the piston ring wear. The test load, sliding velocity and quantity of oil were chosen as the process parameters for conducting of wear test in the wear testing machine. The output response would be the weight loss of the piston ring, which representing the wear of the piston rings. The detailed levels of the process parameters in the wear testing are given in Table 4. 
Table 4: Process Parameters and Their Levels

\begin{tabular}{|l|c|c|c|c|}
\hline \multirow{2}{*}{ Factors } & \multirow{2}{*}{ Symbols } & \multicolumn{3}{c|}{ Levels } \\
\cline { 3 - 5 } & & $\mathbf{- 1}$ & $\mathbf{0}$ & $\mathbf{1}$ \\
\hline Load in N & $\mathrm{A}$ & 50 & 60 & 70 \\
\hline Sliding Velocity in cm / minutes & B & 1200 & 1500 & 1800 \\
\hline Quantity of oil in ml & C & 10 & 20 & 30 \\
\hline
\end{tabular}

\section{Development of Mathematical Model}

The MINITAB14 software was used for design of experiments and graphical analysis of the data. The mathematical model is developed for wear of piston ring under SAE15W40 and Jatropha oil. The wear of piston ring is identified by the weight loss. The value of weight loss of piston ring under SAE15W40 oil was taken as output response. The predicted response of piston ring weight loss was derived by the response surface regression polynomial equation (1).

Weight loss of piston ring, WL (SAE15W40 oil)

$$
=\Delta_{0}+\Delta_{1} A+\Delta_{2} B+\Delta_{3} C+\Delta_{4} A^{2}+\Delta_{5} \mathrm{~B}^{2}+\Delta_{6} \mathrm{C}^{2}+\Delta_{7} A B+\Delta_{8} A \mathrm{C}+\Delta_{9} \mathrm{BC}
$$

Where WL is the predicted response of weight loss of piston ring, $\Delta_{0}$ is model constant and $\Delta_{1}, \Delta_{2}, \Delta_{3}, \Delta_{4}, \Delta_{5}, \Delta_{6}$, $\Delta_{7}, \Delta_{8}$, and $\Delta_{9}$ are coefficients related with variables $\mathrm{A}, \mathrm{B}$ and $\mathrm{C}$ and their interactions were investigated with the help of linear regression method.

The value of weight loss of piston ring under Jatropha oil was taken as output response. The predicted response for piston ring weight loss was calculated by the use of the response surface regression polynomial equation (2).

Weight loss of piston ring, WL (Jatropha oil)

$$
=\partial_{o}+\partial_{1} A+\partial_{2} B+\partial_{3} C+\partial_{4} A^{2}+\partial_{5} \mathrm{~B}^{2}+\partial_{6} \mathrm{C}^{2}+\partial_{7} A B+\partial_{8} A \mathrm{C}+\partial_{9} \mathrm{BC}
$$

Where WL is the predicted response of weight loss of piston ring, $\partial_{o}$ is model constant and $\partial_{1}, \partial_{2}, \partial_{3}, \partial_{4}, \partial_{5}, \partial_{6}, \partial_{7}$, $\partial_{8}$, and $\partial_{9}$ are coefficients associated with variables $\mathrm{A}, \mathrm{B}$ and $\mathrm{C}$ and their interactions were investigated with the help of linear regression method.

\section{RESULTS AND DISCUSSIONS}

The accuracy of the model was developed by substituting the experimental data in the model equation at various conditions of test load, sliding velocity and quantity of oil and the corresponding predicted values of weight loss of piston ring both under SAE 15W40 and Jatropha oil were obtained in the following table 5 and table 6.

\begin{tabular}{|c|c|c|c|c|c|}
\hline \multirow{2}{*}{$\begin{array}{c}\text { Experiment } \\
\text { No }\end{array}$} & \multirow{2}{*}{$\begin{array}{c}\text { Test Load } \\
\text { (N) }\end{array}$} & \multirow{2}{*}{$\begin{array}{c}\text { Sliding } \\
\text { Velocity } \\
(\mathrm{cm} / \mathrm{min})\end{array}$} & \multirow{2}{*}{$\begin{array}{l}\text { Quantity of } \\
\text { Oil (ml) }\end{array}$} & \multicolumn{2}{|c|}{ Weight Loss of Piston Ring (mg) } \\
\hline & & & & $\begin{array}{l}\text { Experimental } \\
\text { Value }\end{array}$ & Predicted Value \\
\hline 1 & 60 & 1800 & 30 & 0.0053 & 0.0052625 \\
\hline 2 & 60 & 1800 & 10 & 0.0056 & 0.0055875 \\
\hline 3 & 60 & 1500 & 20 & 0.0045 & 0.0046333 \\
\hline 4 & 60 & 1500 & 20 & 0.0046 & 0.0046333 \\
\hline 5 & 60 & 1200 & 30 & 0.0040 & 0.0040125 \\
\hline 6 & 70 & 1200 & 20 & 0.0041 & 0.0041125 \\
\hline
\end{tabular}

Table 5: Experimental Layout for Wear Test under Sae15w40 Oil 


\begin{tabular}{|c|c|c|c|c|c|}
\hline \multicolumn{7}{|c|}{ Table 5: Contd., } \\
\hline 7 & 70 & 1800 & 20 & 0.0054 & 0.0054625 \\
\hline 8 & 50 & 1500 & 10 & 0.0050 & 0.0050250 \\
\hline 9 & 70 & 1500 & 30 & 0.0047 & 0.0046750 \\
\hline 10 & 60 & 1500 & 20 & 0.0048 & 0.0046333 \\
\hline 11 & 70 & 1500 & 10 & 0.0050 & 0.0049500 \\
\hline 12 & 50 & 1800 & 20 & 0.0055 & 0.0054875 \\
\hline 13 & 50 & 1500 & 30 & 0.0047 & 0.0047500 \\
\hline 14 & 50 & 1200 & 20 & 0.0043 & 0.0042375 \\
\hline 15 & 60 & 1200 & 10 & 0.0042 & 0.0042375 \\
\hline
\end{tabular}

The figure 2 shows that the predicted values for the piston ring weight loss and the actual values of weight loss of piston ring were quiet closed with each other under SAE15W40 oil. This validated the credibility of the model developed for establishing a correlation between the process variables and eight loss of piston ring under SAE15W40 oil.

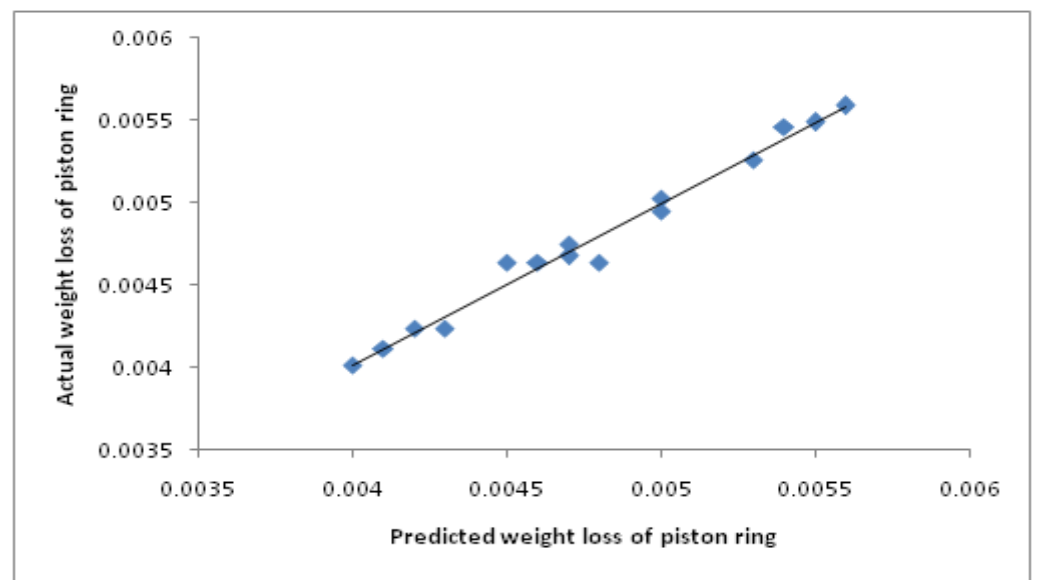

Figure 2: Actual Value Vs Predicted Value for Weight Loss of Piston Ring under SAE15W40 Oil

Table 6: Experimental Layout for Wear Test under Jatropha Oil

\begin{tabular}{|c|c|c|c|c|c|}
\hline \multirow[b]{2}{*}{$\begin{array}{c}\text { Experiment } \\
\text { No }\end{array}$} & \multirow[b]{2}{*}{$\begin{array}{l}\text { Test Load } \\
(\mathbf{N})\end{array}$} & \multirow[b]{2}{*}{$\begin{array}{l}\text { Sliding Velocity } \\
(\mathrm{cm} / \mathrm{min})\end{array}$} & \multirow[b]{2}{*}{$\begin{array}{l}\text { Quantity of } \\
\text { Oil (ml) }\end{array}$} & \multicolumn{2}{|c|}{ Weight Loss of Piston Ring (mg) } \\
\hline & & & & $\begin{array}{c}\text { Experimental } \\
\text { Value }\end{array}$ & $\begin{array}{l}\text { Predicted } \\
\text { Value }\end{array}$ \\
\hline 1 & 60 & 1800 & 30 & 0.0048 & 0.0049 \\
\hline 2 & 60 & 1800 & 10 & 0.0051 & 0.00505 \\
\hline 3 & 60 & 1500 & 20 & 0.0041 & 0.004167 \\
\hline 4 & 60 & 1500 & 20 & 0.0042 & 0.004167 \\
\hline 5 & 60 & 1200 & 30 & 0.0034 & 0.00345 \\
\hline 6 & 70 & 1200 & 20 & 0.0036 & 0.0037 \\
\hline 7 & 70 & 1800 & 20 & 0.0049 & 0.00495 \\
\hline 8 & 50 & 1500 & 10 & 0.0045 & 0.00465 \\
\hline 9 & 70 & 1500 & 30 & 0.0044 & 0.00425 \\
\hline 10 & 60 & 1500 & 20 & 0.0042 & 0.004167 \\
\hline 11 & 70 & 1500 & 10 & 0.0046 & 0.0046 \\
\hline 12 & 50 & 1800 & 20 & 0.0050 & 0.0049 \\
\hline 13 & 50 & 1500 & 30 & 0.0042 & 0.0042 \\
\hline 14 & 50 & 1200 & 20 & 0.0038 & 0.00375 \\
\hline 15 & 60 & 1200 & 10 & 0.0042 & 0.004125 \\
\hline
\end{tabular}

The figure 3 shows that the predicted values for the piston ring weight loss and the actual values of weight loss of piston ring were quiet closed with each other under Jatropha oil, thus, validating the credibility of the model developed for 
establishing a correlation between the process variables and eight loss of piston ring under Jatropha oil.

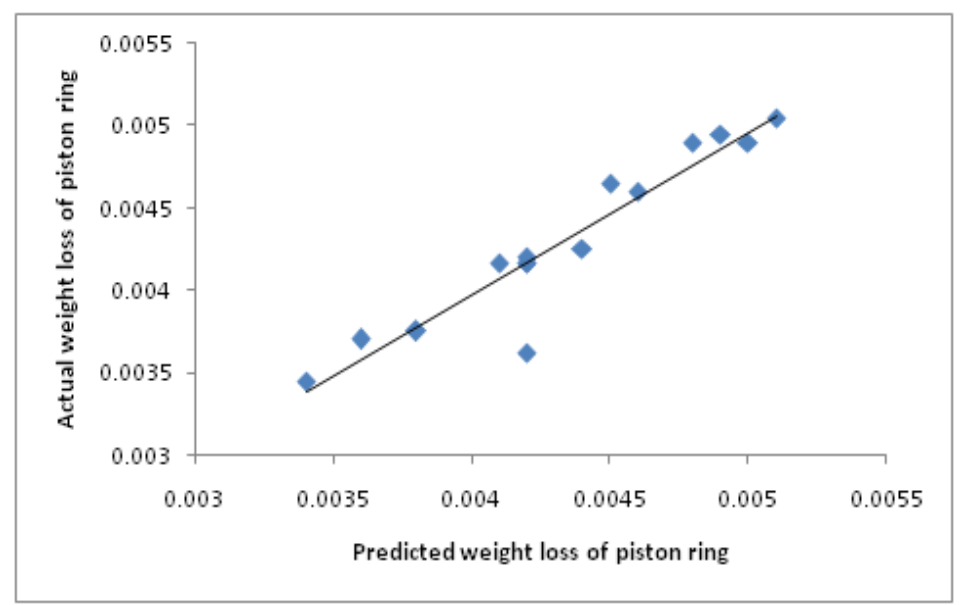

Figure 3: Actual Value Vs Predicted Value for Weight Loss of Piston Ring under Jatropha Oil

From the experimental layout for both wear under SAE15W40 oil and Jatropha oil, it was concluded that the combinations of process parameters such as test load of $60 \mathrm{~N}$, sliding speed of $1200 \mathrm{~cm} / \mathrm{min}$ and $30 \mathrm{ml}$ of oil yields low value of weight loss of piston ring. But Jatropha oil yields low value of weight loss of piston ring as $0.0034 \mathrm{mg}$ when compared to the SAE15W40 oil which yields the weight loss of the piston ring as $0.004 \mathrm{mg}$ at the same process parameter combinations.

Table 7: Anova Table for Wear Test under Both the Sae15w40 Oil and Jatropha Oil

\begin{tabular}{|l|l|c|c|c|c|}
\hline $\begin{array}{c}\text { Dependent } \\
\text { Outcome }\end{array}$ & \multicolumn{1}{|c|}{$\begin{array}{c}\text { Independent Measure that Have Significant } \\
\text { Partial Regression Coefficients }\end{array}$} & Std. Error & F & P & Adj R $\mathbf{R}^{\mathbf{2}}$ \%) \\
\hline \multirow{2}{*}{$\begin{array}{l}\text { Wear test under } \\
\text { SAE15W40 oil }\end{array}$} & Sliding velocity (B) & 12 & 64.08 & 0.000 & 90.01 \\
\cline { 2 - 6 } & Test Load (A) & 12 & 0.11 & 0.895 & 1.3 \\
\cline { 2 - 7 } & Quantity of oil (C) & 12 & 0.29 & 0.755 & 4.7 \\
\hline \multirow{2}{*}{$\begin{array}{l}\text { Wear test under } \\
\text { Jatropha oil }\end{array}$} & Sliding velocity (B) & 12 & $28 . .44$ & 0.000 & 82.58 \\
\cline { 2 - 6 } & Test Load (A) & 12 & 0.05 & 0.95 & 0.85 \\
\cline { 2 - 7 } & Quantity of oil (C) & 0.77 & 0.486 & 11.34 \\
\hline
\end{tabular}

The major factors for wear test for both under SAE15W40 oil and Jatropha oil were identified by analysis of variance (ANOVA) technique. The purpose of the analysis of variance was to investigate the influences of process parameters on the weight loss of piston ring under the both SAE15W40 oil and Jatropha oil. The values of F calculated (Fisher distribution) are compared with F critical at various Degrees of Freedom. However,(Prob>F) value of 0.05 or less indicates that the model equation or model terms were significant. The sliding velocity (B) was more significant model terms at $95 \%$ confidence level. The sliding velocity (C) has (Prob>F) value of 0.000 for wear test for both under SAE15W40 oil and Jatropha oil as shown in table 7. From this statically analysis, sliding velocity (B) is the most important parameter influence the weight loss of piston ring under both under SAE15W40 oil and Jatropha oil.

\section{Interaction Effect}

Figure shows three dimensional (3D) response contour effects of input parameters on the weight loss of piston ring. The figure shows the contour effects of speed and load on the weight loss of piston ring. The variations of the piston ring weight loss with the various kinds of test conditions were plotted as wear maps as shown in figures 4, 5, 6 and 7 . 


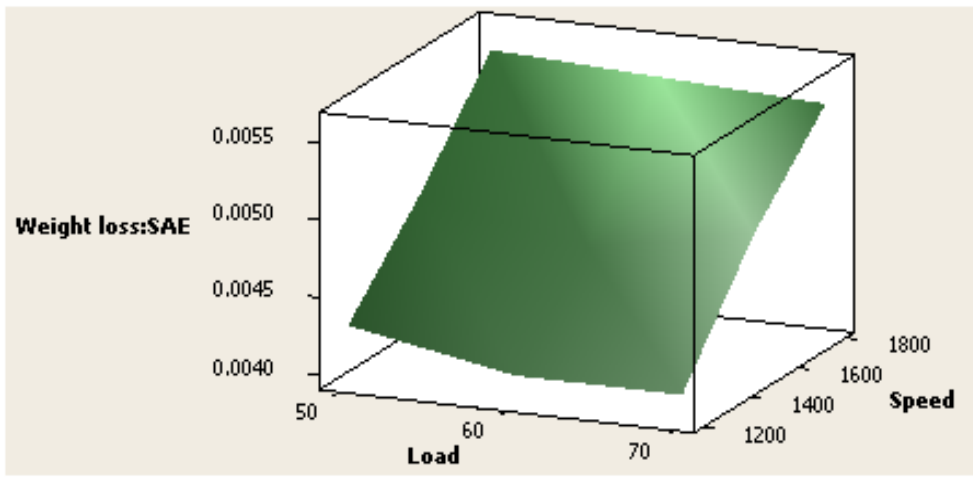

Figure 4: Wear Map of Piston Ring with Different Load With Various Sliding Velocity under SAE15W40 Oil

The figure 4 shows the wear map of piston ring with different load with various sliding speed under the SAE15W40 lubricating oil. It demonstrates that a low weight loss of the piston ring was obtained as 0.004 at low load and at low sliding velocity and the weight loss is gradually increased with increase in the sliding velocity and normal load. It was showed that the maximum weight loss of the piston ring was experienced at sliding speed of $1800 \mathrm{~cm} / \mathrm{min}$ and at a load of $70 \mathrm{~N}$ as 0.0056 .

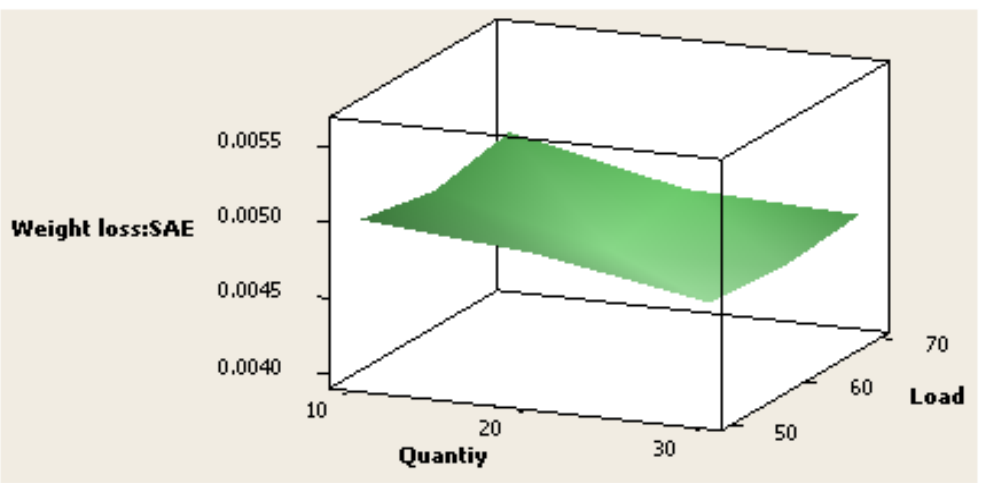

Figure 5: Wear Map of Piston Ring with Quantity of Oil with Various Loads Under SAE15W40 Oil

The figure 5 shows the wear map of piston ring with quantity of oil with various loads under the SAE15W40 lubricating oil. It demonstrate that a low value of weight loss of piston ring obtained as 0.004 at high quantity of SAE15W40 oil and low load and weight loss gradually raises as the normal load increases and quantity of SAE15W40 lubricating oil gets decreased. It was showed that the maximum weight loss experienced at a load of $60 \mathrm{~N}$ and at quantity of oil as $10 \mathrm{ml}$ as 0.0056 . 


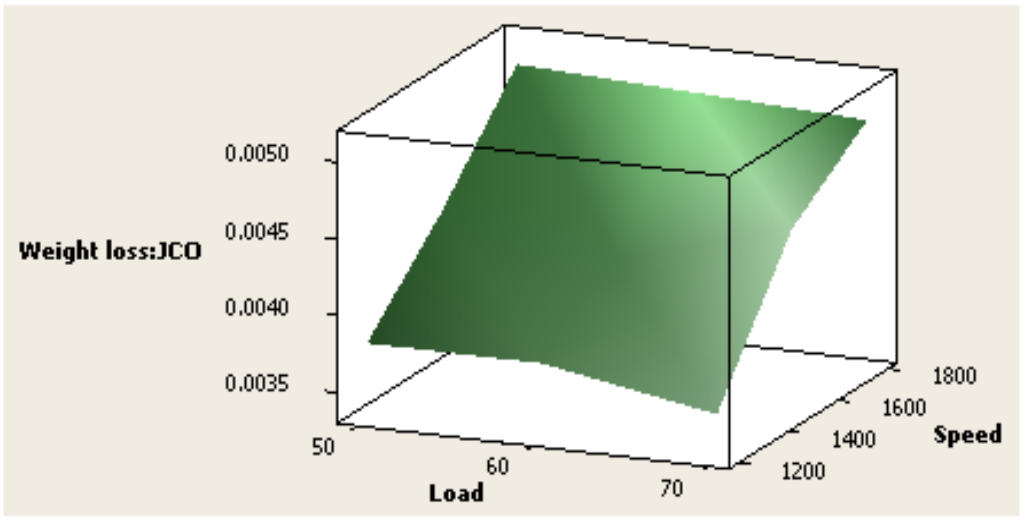

Figure 6: Wear Map of Piston Ring with Different Load with Various Sliding Velocity under Jatropha Oil

The figure 6 shows the wear map of piston ring with different load with various sliding speed under the Jatropha oil. It demonstrate that weight loss of piston ring was obtained as 0.0034 at low load and at low sliding velocity and weight of the piston ring is gradually raises as the sliding velocity and normal load increased. It was showed that the maximum weight loss occurred at sliding speed of $1800 \mathrm{~cm} / \mathrm{min}$ and at a load of $70 \mathrm{~N}$ as 0.0051 .

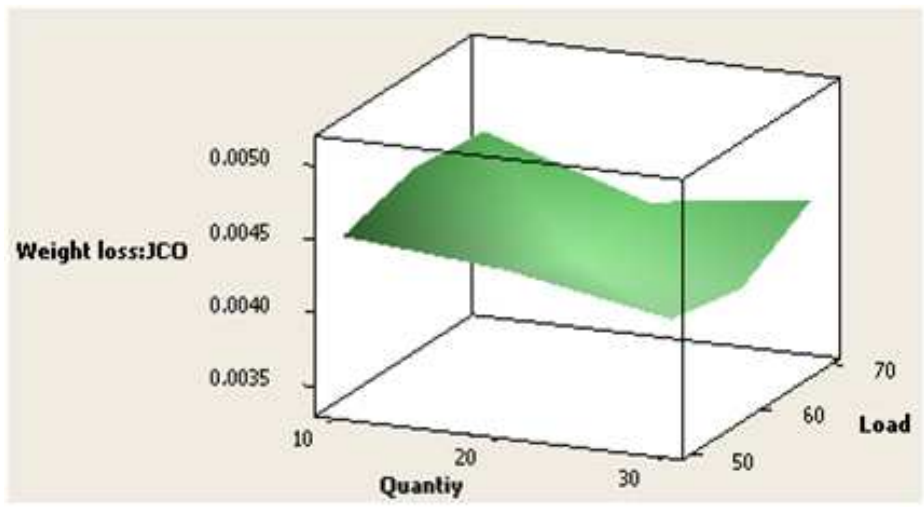

Figure 7: Wear Map of Piston Ring with Quantity of Oil with Various Loads under Jatropha Oil

The figure 7 shows the wear map of piston ring with quantity of oil with various loads under the Jatropha oil. It demonstrates that at high quantity of Jatropha oil and low load a low weight loss were experienced as 0.0034 and weight loss gradually increases as the normal load increases and quantity of Jatropha oil gets decreased. It was showed that the maximum weight loss occurred at a load of $60 \mathrm{~N}$ and at quantity of oil as $10 \mathrm{ml}$ as 0.0051 .

\section{CONCLUSIONS}

The Response surface methodology was applied in this study, to optimize the reciprocating wear tests for piston ring under different oils such as SAE15W40 oil and Jatropha oil. The results were summarized as follows:

The Response surface methodology design was suitable for analysing the wear behaviour of piston ring and cylinder liner pair. The optimal parameters can be found to be lowest level of load, lowest level of sliding velocity and highest level of quantity of oil. The tests under Jatropha oil gave less weight loss of piston rings when compared with that of under SAE15W40 lubricating oil. Moreover, the analysis of variance revealed that the sliding velocity greatly contributed for controlling the wear behaviour of the piston ring. 


\section{REFERENCES}

1. Tung SC, McMillan ML. Automotive tribology overview of current advances and challenges for the future. Tribology International 2004; 37:517-536.

2. R. C. Singh, Roop. Lal, Ranganath M S, Rajiv Chaudhary. A Failure of piston in IC engine: A review. International Journal of Modern Engineering Research 2014; 4: 1-10.

3. Pankaj Sharma, Pratesh Jayaswal. Wear Rate Measurement (IC Engine) Using Lubricant Oil Testing Method. International Journal of Research in Engineering \& Applied Sciences 2012; 2: 21 -37.

4. Yeow-Chong Tan, Zaidi Mohd Ripin. Frictional behaviour of piston rings of small utility two-stroke engine under secondary motion of piston. Tribology International 2011; 44: 592-602.

5. Atul Dhar, Avinash Kumar Agarwal, Vishal Saxena. Measurement of dynamic lubricating oil film thickness between piston ring and liner in a motored engine. Sensors and Actuators A: Physical 2009; 149: 7-15.

6. Monaghan ML. Combustion engines reduction of friction and wear. Inst mech eng conf pub; 1989-9. Paper 1-5.

7. Parker DA, Adams DR. Friction losses in the reciprocating internal combustion engine, tribology key to the efficient engine. Inst mech eng conf pub; 1982-1. Paper C5r82; 1982; 31-39.

8. Monaghan ML. Engine friction a change in emphasis. 2nd BP tribology lecture: inst mech eng 1987.

9. R. Pesic, A. Davinic, S.Veinovic. Methods of Tribological Improves and Testing of Piston engines, Compressors and Pumps. Tribology in Industry 2005; 27: 38-47.

10. H. Mitsuru, B. Yasukazu. A study of piston friction force in an internal combustion engine. ASLE Trans. 1987; 30: 444-451.

11. M. Takiguchi, K. Machida, S. Furuhama, Piston friction force of a small high speed gasoline engine. J. Tribology Trans. 1988; ASME 110: 112-118.

12. G.D. Knoll, H.J. Peeken. Hydrodynamic lubrication of piston skirts. J. Lub. Tech.1982; Trans. ASME 104: 504-509.

13. M. Nakada. Trends in engine technology and tribology. Tribology Int.1994; 27: 3-8.

14. Han D.C., Lee J.S. Analysis of piston ring lubrication with the new boundary condition. Tribology International 1998; 31 (12): 753-760.

15. Murat Kapsiz, Mesut Durat, Ferit Ficici. Friction and wear studies between cylinder liner and piston ring pair using Taguchi design method. Advances in Engineering Software 2011; 42: 595-603.

16. Jumat S, Nadia S, Emad Y. Biolubricants: Raw materials, chemical modifications and environmental benefits. Eur. J. Lipid Sci. Technol. 2010; 112: 519-530.

17. Banerji AR, Chowdhury G, Misra G, Sudarsanam SC, Varma GS, Srivastava GS. Jatropha seed oil for energy. Biomass 1985; 8: $277-282$.

18. Shah GC, Yadav M, Tiwari A. Evaluation of different algal species for the higher production of biodiesel. J. Pet. Technol. Altern. Fuels 2013; 4(1): 1-6.

19. M.B. Karamis, K. Yildizli, H.C, Akirer. Wear behaviour of Al-Mo-Ni composite coating at elevated temperature. Wear 2005; 258: $744-751$.

20. Tung SC, Gaob H. Tribological characteristics and surface interaction between piston ring coatings and a blend of energyconserving oils and ethanol fuels. Wear 2003; 255: 1276-1285. 
21. G. Ryk, I.Etsion. Testing piston rings with partial laser surface texturing for friction reduction. Wear 2006; 261: $792-796$.

22. John J. Truhan, Jun Qu, Peter J. Blau. The effect of lubricating oil condition on the friction and wear of piston ring and cylinder liner materials in a reciprocating bench test. Wear 2005; 259: 1048-1055.

23. J. Michalski, P.Wos. The effect of cylinder liner surface topography on abrasive wear of piston-cylinder assembly in combustion engine. Wear2011; 271: 582-589.

24. Tushar Hire, Dr.V.N. Bertaria. Experimental analysis of piston ring to reduce friction by using different lubricants (sae15w and sae30w) for a four stroke four cylinder petrol. IJARSE 2014; 3 (5): ISSN-2319-8354(E). 116 - 129.

25. Roop Lal, R C Singh, Ranganath M S, S Maji. Friction and Wear of Tribo-Elements in Power Producing Units for IC EnginesA Review. International Journal of Engineering Trends and Technology 2014; 14(5): 225 -231.

26. U.I. Sjodin, U.L.O. Olofsson. Experimental study of wear interaction between piston ring and piston groove in a radial piston hydraulic motor. Wear 2004; 257: 1281-1287.

27. T. H. C. Childs and F. Sabbagh. Boundary Lubricated Wear of Cast Irons to simulate Automotive Piston Ring Wear Rates. Wear 1989; 134: 81 - 97.

28. A. V. Sreenath and N. Raman. Running-in Wear of a Compression Ignition Engine: Factors influencing the Conformance between Cylinder Liner and Piston Rings. Wear 1976; 38: 271 - 289.

29. S. Mezghani, I.Demirci, M.Yousfi, M.ElMansori. Running-in wear modeling of honed surface for combustion engine cylinder liners. Wear 2013; 302: 1360-1369.

30. Priest M, Taylor CM. Automobile engine tribology_approaching the surface. Wear 2000; 241(2):193-203.

31. Staffan Johansson, Per H. Nilsson, Robert Ohlsson, Bengt-Goran Rosen. Experimental friction evaluation of cylinder liner/piston ring contact. Wear 2011; 271: 625-633.

32. Priest M, Dowson D, Taylor CM. Predictive wear modelling of lubricated piston rings in a diesel engine. Wear 1999; 231: 89-101.

33. Bilal S, Mohammed-Dabo I., Nuhu M1, Kasim, S., Almustapha I. and Yamusa Y. Production of biolubricant from Jatropha curcas seed oil. Journal of Chemical Engineering and Materials Science 2013; 4(6); 72-79.

34. John J. Truhan, Jun Qu, Peter J. Blau. A ring test to measure friction and wear of heavy duty diesel engine piston rings and cylinder liners using realistic lubricants. Tribology International 2005; 38: 211-218.

35. Javad Zolgharnein, Ali Shahmoradi and Jahan B.Ghasemi, Comparative study of Box-Behnken, Central composite, and Doehlert matrix for multivariate optimization of $\mathrm{Pb}$ (11) adsorption onto Robinia tree levels. 